\title{
Study on Temporary Payment Management System based on Excel Server in Colleges
}

\author{
Yanfeng Liu
}

Shannxi Xueqian Normal University, Xi’an, Shaanxi, 710100

\author{
Keywords: Excel Server, Colleges, Temporary Payment Management System
}

\begin{abstract}
With the rapid development of higher education in our country, the scale of temporary payment in colleges and universities has been gradually expanded, and the loopholes in the payment of payment have gradually become apparent. How to reduce the occupancy rate of temporary funds, control occupancy time reasonably, improve the use efficiency of limited funds in colleges and universities, and effectively prevent the occurrence of financial risks has become a more urgent issue in the financial management of colleges and universities. This paper, based on the principle of temporary payment, uses EXCEL SERVER to complete the structure and module design of the college temporary payment management system, with the aim of improving the management efficiency and management level of temporary payment in colleges and universities.
\end{abstract}

\section{Introduction}

Temporary payment in colleges and universities means all kinds of funds temporarily advanced or prepaid by colleges and universities for teaching, scientific research projects and equipment, which mainly include prepayment for purchasing experimental materials, materials, office supplies, books, equipment and furniture; Basic repairs, equipment maintenance, infrastructure projects and other advance payments; papers layout fees, labor services fees, class fees, travel expenses, training fees, conference fees, due to business abroad and other approved. With the increase of the economic operation of higher education, the amount of contacts increased, the temporary payment increased accordingly. Temporary payment of colleges and universities occupy a large number of liquidity in colleges and universities, thus affecting the normal capital flow in colleges and universities, daily business accounting and orderly financial management. The Financial Regulations of Higher Education Institutions stipulates: "Institutions of higher learning should establish and perfect the internal management system for cash and various kinds of deposits, clear and settle accounts receivables and payments in a timely manner, and suspend accounts for a long period of time; for receivables and temporary unrecoverable receivables Therefore, schools should establish an internal control system in all aspects, strengthen the management and accounting of temporary payments, arrange and use the existing funds for running schools properly, and do a good job in a timely manner The clean-up of credits and debts prompted the healthy and orderly operation of the financial affairs of colleges and universities.

\section{College temporary payment management problems}

Temporary payment of colleges and universities is mainly divided into educational undertakings and research projects such as temporary payment. Temporary payment of educational undertakings mainly includes: temporary payment of wages, medical temporary payment of public medical expenses, temporary purchase of acquisition fees (including fixed assets and books purchase), laboratory maintenance, network construction, infrastructural projects, temporary payment of campus greening environment and reserve funds, Faculty training, overseas visits and other projects. The temporary payment for research projects mainly includes: research cooperation fee, experimental materials, travel expenses of staff and workers, and temporary payment of equipment and instruments. According to the survey statistics, taking the author's school as an example, the total receivables and temporary payments in 2009 totaled 14.11 million yuan. The balance of 
accounts receivable and temporary payments in 2010 was 15.97 million yuan. Due in 2011 and The balance of temporary payment was 19.6 million yuan. The balance of accounts receivable and temporary payment in 2012 was 23.09 million yuan. The balance of accounts receivable and temporary payments in 2013 was 21.86 million yuan. The growth rate from 2009 to 2010 was 13.18\%, the growth rate from 2010 to 2011 was 22.73\%, the growth rate from 2011 to 2012 was $17.81 \%$, and the growth rate from 2012 to 2013 was $-5.62 \%$. The number of college temporary payment increased year by year, and aging longer, is a common phenomenon in college finance. Colleges and universities in the teaching of fixed assets procurement or transfer of funds for scientific research projects, often require schools to prepay by the form of funds will be transferred to the other account before issuing the corresponding invoices to be charged. Due to the weak financial awareness, borrowers who handled the related business neglected financial blunders or even transferred their original units to the original unit, and still did not reimburse the debts, resulting in the long-term suspension of accounts, resulting in a backlog of large amounts of funds. With the continuous development of education, most university teachers in recent years, in addition to normal teaching work, the corresponding research projects undertaken by universities and colleges include vertical research projects and research funding for horizontal financing, which shows an increasing trend. In the meantime, borrowing operations such as experimental materials for research cooperation and writing, research travel expenses, prepayments and purchase prepay for large equipment have been increasingly frequent. Therefore, the temporary payment of research business accounts for a relatively large proportion of the entire payment. Some college faculty members changed the use of borrowing without approval after borrowing, that is, they did not use the funds in strict accordance with the purpose of borrowing specified in the temporary payment. Temporary payment failed to strictly enforce the "one thing one by one, a clear one thing" requirement, contrary to the provisions of the financial system. In addition, in the daily accounting business accounting found that some university researchers in the name of research funding to borrow money or to purchase experimental supplies in the name of borrowing, but actually the payment of personal labor costs by non-use phenomenon.

\section{Design of Excel Server - based Temporary Payment System and Countermeasures}

Basic information module design. The module includes the loan personnel information and the budget item information. The loan personnel information includes serial number, mnemonic code, borrower number, name, department attribute, department, ID number, salary account, contact information, credit term, credit limit For reference, 12 fields of information, including the borrower number, name, ID number for the lock information, not allowed to modify the other field information can be modified to maintain. In order to reduce the workload of the basic data, mnemonic and reference information field information can be obtained automatically using the function.

The realization of the department to select the input, that is, the drop-down box of the field of the department column can be based on the department attributes corresponding to all such department, select the department can be entered. CB18 is a department attribute cell in the formula, and uses the MATCH function to locate the position of the sector attribute shown in CB18 in the sector attribute field to determine the column offset, and calculates the number of rows of the area to be referenced after offset by using the COUNTA function. By using the OFFSET function The leftmost field of the department attribute is offset and referenced by the reference system to obtain a new reference area, and similarly, the selection and selection of the budget item can be input.

Data entry module design. The data entry module is divided into three sections: loan entry, repayment entry and data summary. The data summary is automatically generated and hidden in the worksheet. (1) The loan entry interface is divided into three areas: loan information entry, borrower information inquiry and current loan limit control. The information to be entered in the loan information entry area includes loan number, department attribute, department, budget item, borrower code, The borrower, the date of the loan, the amount of the loan, the summary, the credit period, and the repayment period of 11 fields, of which the borrowing number field is the initial 
setting and can not be changed after the lockout. The three fields of department attribute, department and budget item are selected for input. The code field queries the borrower information query area for input, borrower, credit period, repayment period of three fields for the automatic generation of input, the date of the loan, abstract, the amount of the borrowed three fields manually entered. In the borrower's information inquiry area, the financial officer can inquire all the employee information consistent with the mnemonic by inputting the borrower's mnemonic code and select the corresponding borrower to verify the identity information.

To strengthen the management of temporary payments, we must formulate and improve corresponding management measures. First of all, the basic principle of public funds should be adhered to. All temporary payments should be handled in accordance with the prescribed procedures. On the loan slip must state the reasons for the loan and write-off time, and according to the provisions of the provisional payment authority for approval. Secondly, to ensure that "one thing, one thing is clear," you can not mix or use one at a time to avoid confusion in the management of temporary payments. Thirdly, the temporary payment should be insisted on written off on time, requiring that "the former account is not clear and the latter accounts not to be borrowed", and in case of special circumstances, it shall be subject to the approval of the relevant competent leadership and the competent financial leadership. The borrowed money should be reimbursed timely within the time limit. Where the deadline for reimbursement of the loan exceeds the deadline, the next month's salary will be deducted until the borrowed amount is deducted. College faculty transferred out, go abroad and other procedures for departure, you must first go to the Finance Department to clean up all my borrowings or go to another name. In each fiscal year to conduct a comprehensive cleanup of interim payments, the suspension of more than three years of payment must identify the corresponding reasons, put forward the views on the processing of overdue temporary payments, reported to the head of the school to make management measures approved. Identified as unable to resolve ganuk grams, analysis of the factors that failed to clean up, and submitted the corresponding manual.

We will step up publicity on temporary payment business knowledge so that teachers and students in all levels will understand the role and management of temporary payments and raise awareness about the management of temporary payments. Understand the scope of borrowings, the amount of borrowings, the repayment period and the penalties for lagging repayment, so as to enhance the sense of ownership of teachers and students and safeguard the fundamental interests of the school. In the meantime, the finance department should improve its working methods and adhere to the principle of no-budget loans and over-budget loans. Periodical clean-up of the temporary payment of various departments, the overdue uncleared and a large amount of long-term loans, stop all expenses of the department, and charge a certain percentage of the fund occupation fee. The deadline to settle, depending on the circumstances of its annual performance evaluation.

It is imperative to clarify and implement the relevant responsibilities of borrowers, borrowers and accountants of financial departments within the institutions of higher learning. First of all, the heads of various departments during the term of the loan approval, at the same time have the obligation to report and recover the debt, and to assume joint and several liability, leave the office to be approved during the term of non-written-off loans transferred to the next term. When the borrower can not pay the repayments on time, the approver should bear joint and several liability. Second, all the borrowers who sign the loan certificate must be responsible for the loan and write off the reimbursements or repayments on schedule. Otherwise, they will be punished according to the relevant regulations of the school. The financial department should carry out the borrower "before the account is not clear, after the account does not borrow" system, control the number of loans. Thirdly, each financial officer should firmly establish the sense of responsibility for the payment of temporary payments, actively promote the payment management system, strictly check the debts, and make the same loss as a result of the improper examination, and the same shall be punished. Only by having a clear responsibility and establishing a responsibility control mechanism can we shoulder our due responsibilities and make every effort to eliminate the provisional payments. 


\section{Conclusion}

In terms of accounting business, the accounting treatment of interim payments occurs frequently, the settlement is complicated and involves a wide range of issues, and the specific management has its own particularity. The management and control of the interim payment is a systematic project that requires the coordination, cooperation and mutual supervision of various departments within the university. At the same time, the regulatory mechanism has been introduced from the outside to effectively strengthen the effective control over the payment of provisional payments, improve the efficiency of the use of limited funds in universities and promote the virtuous circle of funds. After testing, each module of this system has reasonable design, stable performance, correct formula and logical relationship, can meet the requirement of standardized management of temporary payment, and improve the efficiency and management level of college temporary payment management.

\section{Acknowledgements}

2017 Preschool Teachers College of Shaanxi Province-level scientific research projects, subject name: Excel Server in university financial management applications, subject code: 2017YBRS049

\section{References}

[1] Wang Jianhua. Reflections on the receivables and temporary payment management of colleges and universities [J]. Era economy and trade. 2016 (15)

[2] Xiao Hongmei. College temporary payment management problems and countermeasures [J]. Contemporary Accounting. 2014 (08)

[3] Wang Bin. Reflections on the compression and digestion of financial interim payments [J]. Rural Finance and Finance. 2014 (03)

[4] Jie Jie, Liu Lihua. Tentative analysis of college payment management [J]. China market. 2014 (05)

[5] zhang Li, chen Liangfeng. Research on Key Links in Effective Control of Receivables and Temporary Payment in Colleges and Universities [J]. China Township Enterprises Accounting. 2013 (04)

[6] Yu Aijuan. Risk-oriented management of colleges and universities temporary payment management standardization [J]. Business Accounting. 2013 (07) 